(c) American Dairy Science Association, 2005.

\title{
Effect of Antioxidant ( $\alpha$-Tocopherol and Ascorbic Acid) Fortification on Light-Induced Flavor of Milk
}

\author{
M. van Aardt, ${ }^{1}$ S. E. Duncan, ${ }^{1}$ J. E. Marcy, ${ }^{1}$ T. E. Long, ${ }^{2}$ \\ S. F. O'Keefe, ${ }^{1}$ and S. R. Nielsen-Sims ${ }^{3}$ \\ ${ }^{1}$ Department of Food Science and Technology, and \\ ${ }^{2}$ Department of Chemistry, Virginia Polytechnic Institute and State University, \\ Blacksburg 24061 \\ ${ }^{3}$ Eastman Chemical Co., Kingsport, TN 37662-5125
}

\section{ABSTRACT}

The effectiveness of added antioxidants against oxidation off-flavor development in light-exposed milk was evaluated using sensory and chemical analysis. Sensory testing for similarity showed no perceivable difference between control milk and milk with added (1) $0.05 \% \alpha$-tocopherol (TOC) and (2) $0.025 \% \alpha$-tocopherol and $0.025 \%$ ascorbic acid (TOC/ASC), but did demonstrate a perceivable difference when adding (3) $0.05 \%$ ascorbic acid (ASC) alone. Subsequently, sensory testing for difference showed a significant difference in oxidation off-flavor between light-exposed control milk and light-exposed milk with added TOC/ASC, whereas milk fortified with TOC was not different from control. Gas chromatography-olfactometry showed that more aroma-active flavor compounds were observed in lightexposed milk treated with TOC and TOC/ASC than light-exposed milk with no added antioxidants. The thiobarbituric acid reactive substances (TBARS) test verified chemically the extent of oxidation in control and antioxidant-treated milk samples. Milk that was exposed to light for $10 \mathrm{~h}$ showed a significantly higher TBARS value $(0.92 \pm 0.09 \mathrm{mg} / \mathrm{kg})$ than milk that was protected from light $(0.59 \pm 0.184 \mathrm{mg} / \mathrm{kg})$, or milk that was treated with TOC/ASC $(0.26 \pm 0.092 \mathrm{mg} / \mathrm{kg})$. Direct addition of low levels of antioxidants (TOC/ASC) to milk protected its flavor over $10 \mathrm{~h}$ of light exposed storage. (Key words: light-induced flavor, lipid oxidation, milk, antioxidant)

\begin{abstract}
Abbreviation key: ASC = ascorbic acid, GC-MS = gas chromatography-mass spectrometry, GC-O = gas chromatography-olfactometry, $\mathbf{H}_{\mathbf{0}}=$ null hypothesis, $\mathbf{H}_{1}=$ alternative hypothesis, $\mathbf{T B A R S}=$ thiobarbituric acid reactive substances, $\mathbf{T O C}=\alpha$-tocopherol.
\end{abstract}

Received June 1, 2004.

Accepted December 1, 2004

Corresponding author: Susan Duncan; e-mail: duncans@vt.edu.

\section{INTRODUCTION}

Oxidative reactions in milk are detrimental because these reactions reduce the nutritional value of milk and contribute to a reduction in shelf life. Milk oxidation can be catalyzed by certain metals, and light exposure, or it may occur spontaneously. Both milk fat and proteins may undergo oxidation reactions. Whole milk contains approximately $3.25 \%$ fat and $4 \%$ protein. Milk fat consists of approximately $70 \%$ saturated fatty acids, $27 \%$ monounsaturated fatty acids (predominantly palmitoleic and oleic acid), and $4 \%$ polyunsaturated fatty acids (predominantly linoleic acid; Christie, 1983). Phospholipids, as constituents of the milk fat globule membrane, surround milk fat globules in milk and consist of approximately 40 to $60 \%$ unsaturated fatty acids of which one-third are polyunsaturated (Deeth, 1997). Unsaturated lipids undergo auto-oxidation as well as light-induced oxidation, which cause the destruction of several key nutrients such as riboflavin and ascorbic acid and results in off-flavor development (Cadwallader and Howard, 1998). Oxidative changes in proteins and amino acids also result in the development of off-flavors and destruction of key nutrients (Cadwallader and Howard, 1998). Amino acids such as histidine, cysteine, methionine, tryptophan, and tyrosine oxidize in the presence of light, riboflavin, and active oxygen species. Various odorous compounds such as methionine sulfoxide and dimethyl disulfide then form (Jadhav et al., 1996; Cadwallader and Howard, 1998).

Various researchers have reported on the specific compounds responsible for oxidation off-flavors in milk. Cadwallader and Howard (1998) identified dimethyl sulfide, 2-methylpropanal, n-pentanal, n-hexanal, dimethyltrisulfide, and 1-octen-3-one as important odorous oxidation compounds by gas chromatography-olfactometry (GC-O). The respective odor descriptions for these compounds were "canned corn", "dark chocolate", "sour cut-grass", "green cut-grass", "cooked cabbage", and "earthy mushroom". Marsili (1999) reported the same flavor compounds as Cadwallader and Howard (1998) and attributed the development of these flavors 
because of oxidative breakdown of unsaturated fatty acids, particularly those present in the phospholipids, and proteins. Jung et al. (1998) suggested that dimethyl disulfide was mainly responsible for the light-induced off-flavor in skim milk, as supported by sensory testing.

Antioxidants, such as $\alpha$-tocopherol and ascorbic acid, play a crucial role in preventing or delaying oxidation and have attracted much attention as food additives (Madhavi et al., 1996). $\alpha$-Tocopherol is a primary antioxidant functioning by terminating free-radical chain reactions by donating hydrogen or electrons to free radicals and converting them to more stable products (Frankel, 1998). Ascorbic acid is a secondary antioxidant that can be broadly classified as an oxygen scavenger/singlet oxygen quencher, reacting with free oxygen and removing it in a closed system (Madhavi et al., 1996). Certain antioxidants such as tocopherols and ascorbic acid show synergistic action against oxidation (Madhavi et al., 1996). These antioxidants reduce the rate of initiation reactions in the free-radical chain reaction and function at very low concentrations, $0.01 \%$ or less (Madhavi et al., 1996). Although milk contains low concentrations of natural antioxidants, such as $\alpha$-tocopherol (13 to 30 $\mu \mathrm{g} / \mathrm{g}$ of milk fat) and ascorbic acid $(<20 \mathrm{mg} / \mathrm{L})$, processing and storage deplete these natural resources (Rosenthal et al., 1993; Jensen and Nielsen, 1996).

Various studies targeting the control of oxidized flavor in milk have included preharvest approaches, such as injecting $\alpha$-tocopherol in the muscles of dairy cows (Charmley and Nicholson, 1993) or adding $\alpha$-tocopherol to the feed (Focant et al., 1998), and processing approaches that include the addition of ascorbic acid to milk (Rosenthal et al., 1993; Jung et al., 1998). Jung et al. (1998) concluded that dimethyl disulfide was mainly responsible for the light-induced off-flavor in skim milk and that increasing levels of ascorbic acid (from 200 to $1000 \mathrm{ppm}$ ) lowered the formation of dimethyl disulfide and off-flavor development in skim milk. Rosenthal et al. (1993) added ascorbic acid $(1 \mathrm{~g} / \mathrm{mL})$ to whole milk (approximately 3.5\% milk fat) to evaluate milk fat stability. Sensory results showed that these levels of ascorbic acid negatively impacted milk flavor. In addition, no differences in oxidation levels were observed in fortified milk [thiobarbituric acid reactive substances (TBARS) value $=0.61 \mathrm{mg} / \mathrm{kg}$ ] and control milk (TBARS value $=0.71 \mathrm{mg} / \mathrm{kg}$ ) over $7 \mathrm{wk}$ of storage in the dark. Yang (1994) reported that ascorbic acid chemical quenching rate of singlet oxygen was $1.53 \times 10^{8}$ at $\mathrm{pH}$ $4.0,1.86 \times 10^{8}$ at $\mathrm{pH} 5.6$, and $1.19 \times 10^{8} \mathrm{M} / \mathrm{s}$ at $\mathrm{pH} 7.0$. Bandarra et al. (1999) studied the mechanism responsible for the observed synergy of tocopherols and various phospholipids against fish oil oxidation, and concluded that the highest inhibitory effect against oxidation was shown by the synergy between $\alpha$-tocopherol and phos- phatidylethanolamine. Studies that examined the effect of $\alpha$-tocopherol on the stability of milk fat and offflavor in milk evaluated the degree of oxidation with sensory evaluation or chemical analysis such as the Rancimat method (Charmley and Nicholson, 1993; Focant et al., 1998). Various studies reported on the influence of antioxidants on lipid oxidation products in model oils or oil-in-water emulsion systems by looking at formulation of specific flavor compounds (Huang et al., 1996; Mei et al., 1999; Wessling et al., 1999). However, further research is necessary to show the effect of antioxidants on milk fat oxidation, in terms of formation of specific flavor compounds such as pentanal, hexanal, and 1-octen-3-ol. These compounds are common oxidation compounds found in light-oxidized milk (Kim and Morr, 1996; Cadwallader and Howard, 1998; Marsili, 1999).

The objectives of this study were 1) to determine if the addition of antioxidants to milk changes milk flavor (sensory test for similarity), and decrease oxidation offflavor in milk when exposed to light for $10 \mathrm{~h}$ (sensory test for difference); and 2) to identify aroma-active flavor compounds and rate their intensities using GC-O, and evaluate the extent of oxidation using the TBARS test.

\section{MATERIALS AND METHODS}

\section{Milk Processing}

Fresh raw milk was obtained from the Virginia Tech dairy farm and completely processed within $4 \mathrm{~h}$ of milking. Milk was prewarmed to $55^{\circ} \mathrm{C}$ and separated into cream and skim milk using a pilot plant separator (Elecrem separator, model 1G, $6400 \mathrm{rpm}$, Bonanza Industries, Inc., Calgary, Canada). Milk was standardized at $2 \%$ fat content by adding cream to skim milk in appropriate proportions, and homogenized at $13.6 \mathrm{MPa}$ (10.2 $\mathrm{MPa}$ - first stage; $3.4 \mathrm{MPa}$ - second stage) on a 2-stage homogenizer (Type DX, Cherry Burrel Corp., Delavan, WI). Milk was pasteurized after separation and homogenization to limit contamination after pasteurization. Milk was pasteurized at $63.3^{\circ} \mathrm{C}$ for $30 \mathrm{~min}$ in a vat pasteurizer (P50.8770, Creamery Package Mfg. Co., Chicago, IL) and cooled to $25^{\circ} \mathrm{C}$. Milk was stored at $4^{\circ} \mathrm{C}$ in 40 -L stainless steel containers until needed.

Two separate batches of milk were processed on different days for sensory testing and chemical analysis, respectively. Thiobarbituric acid reactive substances analysis was done in triplicate. Triplicate samples were obtained by spiking antioxidants in 3 separate aliquots from a single processed milk batch. Sensory analysis and GC-O tests were not replicated. Single sensory tests take into account measurement error but not experimental error (Meilgaard et al., 1999). However, because 
the determination of differences between treatment and not between batch was the objective, statistical differences can be inferred.

\section{Preparation of Antioxidant-Spiked Samples}

Chemical grade D- $\alpha$-tocopherol (98\%) and L-ascorbic acid $(99.5 \%)$ were obtained from Fisher Scientific (Cincinnati, OH). For sensory analysis, reduced fat milk was spiked with $0.05 \% \alpha$-tocopherol (TOC), $0.025 \% \alpha$ tocopherol and $0.025 \%$ ascorbic acid (TOC/ASC), and $0.05 \%$ ascorbic acid (ASC), respectively and stored in appropriate stainless steel containers at $4^{\circ} \mathrm{C}$ in a Tonka refrigeration unit (Hopkins, MN) until sensory testing. Because TOC is a viscous fluid, milk was prewarmed to $50^{\circ} \mathrm{C}$ before antioxidants were added and blended vigorously with a hand blender (White Westinghouse, Tulsa, OK) for approximately $30 \mathrm{~s}$. Milk was used for sensory analysis within $2 \mathrm{~d}$ of processing. Sensory testing for similarity was done within $24 \mathrm{~h}$ of processing, because no light treatment was applied. A lag time of $2 \mathrm{~d}$ existed between processing and sensory testing for difference due to the time it took to expose milk samples to $10 \mathrm{~h}$ of light as well as sample preparation for sensory analysis.

\section{Milk Storage and Handling}

For the triangle test for similarity, 10-mL aliquots of control (unspiked) and antioxidant-treated milk samples were poured into $20-\mathrm{mL}$ plastic cups with plastic lids and stored at $4^{\circ} \mathrm{C}$ until sensory testing. For the triangle test for difference, control and antioxidanttreated milk samples were stored in 1-L clear glass containers at $4^{\circ} \mathrm{C}$, while undergoing exposure to fluorescent light. Samples were positioned approximately $15 \mathrm{~cm}$ below a row of fluorescent Econ-o-watt lights in a Tonka refrigeration unit (Hopkins, MN). Light exposure was regulated at intensity of 1100 to $1300 \mathrm{~lx}$, as measured at the top of sample bottles, for $10 \mathrm{~h}$. After light exposure, $10-\mathrm{mL}$ aliquots were poured into $20-\mathrm{mL}$ plastic cups with plastic lids for sensory testing. Milk samples intended for GC-O and the TBARS tests were pipetted (21-mL aliquots) into $40-\mathrm{mL}$ clear glass bottles fitted with Teflon-coated septa (Supelco, Bellefonte, PA). After packaging, samples were exposed to light conditions as described for sensory testing above. Lightprotected control milk was obtained by covering sample bottles with aluminum foil. This treatment was used only in chemical analysis and not sensory analysis.

\section{Sensory Analysis}

A triangle test for similarity was used to determine the effect of antioxidant addition on milk flavor. Simi- larity was tested by comparing control (unspiked) and treated milks (TOC, ASC, and TOC/ASC). The second test was a triangle test for difference, determining the differences in oxidation off-flavor intensity between light-exposed control milk compared with light-exposed treated milks (TOC, ASC, and TOC/ASC). Panelists were instructed to expectorate milk, because chemical grade vitamins were used.

Triangle test for similarity. A panel of 30 volunteers from students, staff, and faculty at the Department of Food Science and Technology at Virginia Tech (Blacksburg, VA) participated in the test. Testing was done in the sensory laboratory within the department. Panelists were seated in individual sensory booths under white lighting. Each panelist was requested to complete a human subject's consent form before testing. Panelists were instructed to rinse with room temperature spring water between each 3-sample set. Each 3sample set included 2 samples of unspiked reduced fat milk (A) and one antioxidant-spiked sample (B) or 2 antioxidant-spiked samples (B) and one unspiked reduced fat milk sample (A). The position of the "odd" sample within the 3 -sample set was randomized to remove positional bias with 6 possible orders represented (AAB, BBA, ABA, BAA, BAB, and ABB). Each panelist was presented with three 3 -sample sets (9 samples total) on one tray and asked to choose the sample that tasted "different" within each 3-sample set (Lawless and Heymann, 1998). This allowed each panelist to evaluate one set of each of the 3 antioxidant treatments (TOC, ASC, TOC/ASC). Sample cups were coded with random 3-digit numbers. Samples were presented at approximately $7^{\circ} \mathrm{C}$.

Triangle test for difference. A panel of 24 volunteers from students, staff, and faculty at the Department of Food Science and Technology at Virginia Tech participated in this test. Testing was done in the same venue and under the same conditions as the similarity testing. Each panelist was presented with two 3-sample sets on one tray and asked to choose the sample that tasted "different" within each 3-sample set (Lawless and Heymann, 1998). This allowed each panelist to evaluate one set of each of the 2 light-exposed antioxidant treatments (TOC, TOC/ASC). Once again, the position of the "odd" sample within the 3-sample set was randomized to remove positional bias with 6 possible orders represented $(\mathrm{AAB}, \mathrm{BBA}, \mathrm{ABA}, \mathrm{BAA}, \mathrm{BAB}$, and $\mathrm{ABB})$. In this test (A) is representative of light-exposed unspiked milk, and (B) represents a light-exposed antioxidant spiked milk sample.

\section{Chemical Analysis}

$\boldsymbol{G C}$ - $\boldsymbol{O}$. Extraction and concentration of volatile compounds were done using solid-phase microextraction. A 
75- $\mu \mathrm{m}$ carboxen poly(dimethyl siloxane)-coated solidphase microextraction fiber (Supelco) was exposed to the milk headspace, with the end of the fiber approximately $1 \mathrm{~cm}$ above the milk surface for $22 \mathrm{~min}$ at $45^{\circ} \mathrm{C}$ with magnetic stirring of the sample. Volatile compounds were desorbed in the injector port of a GC-O system consisting of a HP 5890A GC (Hewlett-Packard Co., Palo Alto, CA) equipped with a flame ionization detector and a sniffing port (ODOII; SGE, Inc., Austin, TX). The injector temperature was $280^{\circ} \mathrm{C}$, and all injections were made in the splitless mode. Separation was completed on a $30-\mathrm{m} \times 0.25-\mathrm{mm}$ i.d. $\times 0.25-\mu \mathrm{m}$ film thickness capillary column (DB-5ms; J\&W Scientific, Folsom, CA) with helium carrier gas flow rates of 35 $\mathrm{cm} / \mathrm{s}$ linear velocity. Column eluent was split 1:1 between the flame ionization detector and sniffing port using deactivated fused silica capillaries (1-m length $\times$ 0.32-mm i.d.). Chromatograms were obtained using a HP integrator (HP 3396A, Hewlett-Packard Co.). The GC oven temperature was programmed from 35 to $180^{\circ} \mathrm{C}$ at a rate of $15^{\circ} \mathrm{C} / \mathrm{min}$, and from 180 to $260^{\circ} \mathrm{C}$ at a rate of $20^{\circ} \mathrm{C} / \mathrm{min}$ with initial, intermediate, and final hold times of $0.5 \mathrm{~min}$, respectively. The flame ionization detector and sniffing port were maintained at $300^{\circ} \mathrm{C}$. The sniffing port was supplied with humidified air at 10 to $15 \mathrm{~mL} / \mathrm{min}$. Because volatile flavor compounds were not quantified, internal or external standards were not used. Gas chromatography-mass spectrometry (GC-MS) (HP 6890, 5973 Mass Selective Detector, Hewlett-Packard Co.) was used to identify volatile compounds in light-exposed milk samples. Separation was completed on a $30-\mathrm{m} \times 0.25-\mathrm{mm}$ i.d. $\times 0.25-\mu \mathrm{m}$ film thickness capillary column (HP-5; Hewlett-Packard Co.). Oven temperature program and conditions were the same as mentioned above. Volatile flavor compounds were identified after comparing retention times with known retention times of flavor compounds from preliminary GC-MS results of light-exposed milk samples.

Training of panelists for GC-O. Six people who regularly participate in GC-O studies were trained in four 20-min sessions before GC-O analysis of treated samples. Two aroma training kits were obtained: (1) Beer Aroma Recognition kit, and (2) Beer Taint Recognition kit (Brewing Research International, United Kingdom). These kits contained a variety of chemical compounds representing odors commonly associated with lipid oxidation (Table 1). During training, panelists were asked to sniff each aroma, practice placing a verbal descriptor with the aroma, and then compare with the identified aroma for each reference standard. Intensities were rated on a scale of 1 (slight odor) to 5 (extreme odor). Results were tabulated as + (0 to 1), ++ ( 2 to 3 ), and +++ (4 to 5). One panelist who consistently
Table 1. Chemical compounds used in gas chromatography-olfactometry training.

\begin{tabular}{ll}
\hline Chemical compound & Aroma $^{1}$ \\
\hline Trans-2-hexenal & Floral \\
Nonanal & Citrus \\
Eugenol & Spicy \\
Hexanal & Grassy \\
1-Octen-3-ol & Mushroom \\
Heptanal & Green \\
1-Octen-3-one & Mushroom/metallic \\
Octanal & Fatty, citrus \\
2,3-Butanedione & Diacetyl \\
Butyric acid & Rancid \\
Isovaleric acid & Cheesy \\
Trans 2-nonenal & Cardboard \\
5-Methyl furfural & Papery \\
Dimethyl disulfide & Cooked vegetable \\
n-Propanethiol & Onion \\
\hline
\end{tabular}

${ }^{1}$ Aroma training kits: Beer Aroma Recognition kit, Beer Taint Recognition kit (Brewing Research International, United Kingdom).

correctly identified aroma compounds was chosen to participate in GC-O of samples.

TBARS. The TBARS test used was modified from Spanier and Traylor (1991), following the direct chemical/extraction method rather than the distillation method. Modifications included: a 10\% (wt/vol) dilution was made by blending $3.0 \mathrm{~g}$ of milk with $84 \mathrm{~mL}$ of water, $9.5 \mathrm{~mL}$ of solution III (propyl gallate and EDTA antioxidant and chelator solution), and $1 \mathrm{~mL}$ of $10 \%$ SDS. No homogenization was done before 1-mL aliquots were combined with $4 \mathrm{~mL}$ of solution I (thiobarbituric acid solution). After incubation in a $95^{\circ} \mathrm{C}$ water bath for $60 \mathrm{~min}, 5 \mathrm{~mL}$ of solution II (n-butanol and pyridine) was added to each sample. Absorbances were read on a double-beam UV spectrophotometer (Hitachi model 150 to 20) (Hitachi High-Technologies, Schaumburg, IL). The TBARS value for samples were calculated by the following equation, where $\mathrm{A}=$ absorbance of sample, $\mathrm{Wt}=$ exact sample weight, and $\mathrm{Ks}=$ constant obtained from the slope of the standard curve.

$$
\text { Sample TBARS }=\mathrm{Ks} \times \mathrm{A} \times 5 / \mathrm{Wt}
$$

\section{Statistical Analysis}

For both similarity and difference tests, data were analyzed by counting the number of correct responses (correctly identified "different" sample) and the number of total responses. These numbers were compared with critical values found in Table 8 in Meilgaard et al. (1999) to determine significant differences. For the similarity test, parameters were defined at $\mathrm{n}=30, \alpha=0.3$, $\beta=0.05$, and $\mathrm{p}_{\mathrm{d}}=30 \%$ and parameters for the difference test were defined at $\mathrm{n}=24, \alpha=0.05, \beta=0.40$, and $\mathrm{p}_{\mathrm{d}}=$ $30 \%$. Similarity testing is done at a lower $\beta$-value to 
Table 2. The null $\left(\mathrm{H}_{0}\right)$ and alternative $\left(\mathrm{H}_{1}\right)$ hypotheses for the sensory similarity and difference tests between milk with $0.05 \% \alpha$-tocopherol, $0.05 \%$ ascorbic acid, and a combination of $0.025 \% \alpha$-tocopherol and $0.025 \%$ ascorbic acid.

\begin{tabular}{lll}
\hline Sensory test & Hypothesis & Result \\
\hline Similarity testing $^{1}$ & $\mathrm{H}_{0}$ : Proportion of correct responses $<12 / 30$ & (no significant difference) \\
& $\mathrm{H}_{1}$ : Proportion of correct responses $\geq 12 / 30$ & $\begin{array}{l}\text { (significant difference) } \\
\text { (no significant difference) } \\
\text { Difference testing }\end{array}$ \\
& $\mathrm{H}_{0}$ : Proportion of correct responses $<13 / 24$ & (significant difference) \\
\hline
\end{tabular}

${ }^{1} \mathrm{n}=30$ Independent observations with $\alpha=0.30, \beta=0.05$, and $\mathrm{p}_{\mathrm{d}}=30$.

${ }^{2} \mathrm{n}=24$ Independent observations with $\alpha=0.05, \beta=0.4$, and $\mathrm{p}_{\mathrm{d}}=30$.

reduce the risk of a Type II error (not rejecting the null hypothesis when it is false; failing to detect a difference that exists). Difference testing is done at a low $\alpha$-value to reduce the risk of a Type I error (rejecting the null hypothesis when it is true; that a difference exists when it does not). For similarity testing, the upper 99\% onesided confidence limit and the $80 \%$ one-sided confidence limit were calculated on the proportion of the population that can distinguish the samples as described in Meilgaard et al. (1999). For difference testing, only the upper $99 \%$ confidence limit was calculated.

The TBARS values were determined by calculating means $(\mathrm{n}=3)$ and standard deviations. ANOVA was used to test the null hypothesis $\left(\mathrm{H}_{0}: \mu_{\text {control-light }}=\mu_{\text {TOC }}=\right.$ $\mu_{\text {TOC/ASC }}$ ), and Tukey's honestly significant difference was used to compare means. Significant differences were defined at $P<0.05$ (SAS Institute, 1998).

\section{RESULTS AND DISCUSSION}

\section{Sensory Analysis}

Similarity testing was done to ensure that the levels of added antioxidant to reduced fat milk in this study were not significantly perceivable by sensory analysis. A low $\beta$-value was chosen to reduce the risk of a Type II error. In this case, a high $\alpha$-value is acceptable to keep the number of assessors within reasonable limits, and accepting the increased risk of a Type I error (Lawless and Heymann, 1998). The general null hypothesis $\left(\mathbf{H}_{\mathbf{0}}\right)$ for triangle sensory tests states that the probability of making a correct selection when there is no perceptible difference between the samples is 1 in 3 . The alternative hypothesis $\left(\mathbf{H}_{\mathbf{1}}\right)$ states that the probability that the underlying population will make the correct decision when they perceive a difference between the samples will be larger than 1 in 3 . This is a one-sided alternative hypothesis, and the test is one-tailed (Lawless and Heymann, 1998). The specific null and alternative hypotheses for the sensory similarity and difference tests are tabulated in Table 2.
Correct identification of "odd" samples in each triangle set is shown in Table 3. The critical number of correct responses in a triangle test is 12 for 30 observations at $\alpha=0.40, \beta=0.05$, and $\mathrm{p}_{\mathrm{d}}=30 \%$. Value $\mathrm{p}_{\mathrm{d}}$ refers to the maximum allowable proportion of distinguishers in the population (Meilgaard et al., 1999). In this study it was assumed that the sensory difference would be moderate, thus justifying the $\mathrm{p}_{\mathrm{d}}=30 \%$.

Similarity testing showed that only 8 and 5 correct selections out of 30 were made when comparing milk flavor of unspiked milk to milk spiked with TOC and TOC/ASC, respectively. The upper $99 \%$ one-sided confidence limit on the proportion of distinguishers for treated milk with TOC or TOC/ASC are 18 and $10 \%$, respectively, and the lower $80 \%$ one-sided confidence limit for both antioxidant treatments falls at $0 \%$. We can conclude that we are $99 \%$ sure that the true proportion of the population that can distinguish the control and treatment (1) samples is no greater than $18 \%$ and may be as low as $0 \%$, whereas we are $99 \%$ sure that the true proportion of the population that can distinguish the control and treatment (2) samples is no greater than $10 \%$ and may be as low as $0 \%$. Therefore we conclude that control milk and milk spiked with TOC or TOC/ASC are sufficiently similar to be used interchangeably (Table 3). However, 13 correct responses out of 30 were made when comparing control milk flavor and milk with ASC added, indicating with 95\% confidence that the proportion of the population who can perceive this difference is more than $30 \%$ and was therefore not meaningful for use in the difference test.

Difference testing was done to determine if there is a perceivable sensory difference in oxidation off-flavor between light-exposed reduced fat milk with and without added antioxidants. Here, a low $\alpha$-value is important to reduce the risk of a Type I error. Table 3 shows the number of correct responses for difference testing. The critical number of correct responses in a triangle test is 13 for 24 observations at an $\alpha$-level of 0.05 (Meilgaard et al., 1999). The number of correct 
Table 3. Sensory triangle test responses for antioxidant-spiked reduced fat milk compared to control (unspiked) milk.

\begin{tabular}{|c|c|c|c|c|}
\hline \multirow[b]{2}{*}{ Treatment } & \multicolumn{2}{|c|}{$\begin{array}{c}\text { Similarity test }{ }^{1} \\
\text { (no light exposure) }\end{array}$} & \multicolumn{2}{|c|}{$\begin{array}{l}\text { Difference test }{ }^{2} \\
\text { (light exposure) }\end{array}$} \\
\hline & $\begin{array}{l}\text { Correct } \\
\text { responses }\end{array}$ & $\begin{array}{l}\text { Confidence } \\
\text { limits } \\
\left(\mathrm{P}_{\max }{ }^{4} \mathrm{P}_{\min }{ }^{5}\right)\end{array}$ & $\begin{array}{l}\text { Correct } \\
\text { responses }\end{array}$ & $\begin{array}{l}\text { Confidence } \\
\text { limits } \\
\left(\mathrm{P}_{\min }^{5}\right) \\
\end{array}$ \\
\hline $0.05 \% \alpha$-tocopherol & $\begin{array}{c}8 \\
13^{3}\end{array}$ & $18 \%, 0 \%$ & 6 & \\
\hline $\begin{array}{l}0.05 \% \text { ascorbic acid } \\
0.025 \% \alpha \text {-tocopherol and } \\
0.025 \% \text { ascorbic acid }\end{array}$ & $\begin{array}{c}13^{\circ} \\
5\end{array}$ & $10 \%, 0 \%$ & $14^{3}$ & $25 \%$ \\
\hline $\begin{array}{l}{ }^{1} \text { Total observations }=3 \\
{ }^{2} \text { Total observations }=2 \\
{ }^{3} \text { Significantly different } \\
{ }^{4} \mathrm{P}_{\text {max }}, \text { upper } 99 \% \text { one-s }\end{array}$ & $\begin{array}{l}\text { lesponse } \\
\text { l response } \\
\text { trol. } \\
\text { fidence limi }\end{array}$ & $\begin{array}{l}\alpha=30, \beta=0 .( \\
\alpha=0.05, \beta=\end{array}$ & $\begin{array}{l}30 \% \\
=30 \%\end{array}$ & \\
\hline
\end{tabular}

responses (correctly identified odd samples) was compared with the critical number of correct responses to indicate significant differences. A significant difference was observed between flavors of light-exposed control milk and milk with TOC/ASC added. However, there was no significant difference in light-exposed control milk flavor and light-exposed milk with $0.05 \% \alpha$-tocopherol.

General remarks on score sheets from panelists that correctly identified the "odd" samples indicated that reduced fat milk treated with a combination of TOC/ ASC showed more fresh milk flavor character than light-exposed milk without added antioxidant. This leads us to believe that the significant difference that was observed between light-exposed control milk and milk treated with TOC/ASC is due to a higher oxidized flavor in control milk. This also supports research by Madhavi et al. (1996) that the synergism between $\alpha$ tocopherol and ascorbic acid results in greater inhibition of oxidation than does each independent antioxidant.

Preharvest technologies aiming to increase natural antioxidant levels in milk as a way of limiting oxidation have received much attention. Charmley and Nicholson (1993) showed a decrease in oxidation flavor in milk from 27.5 to 8.3 on a 140 -point scale $(140=$ extremely oxidized) with increased $\alpha$-tocopherol levels in milk. A combination of oral and intramuscular injections increased the level of $\alpha$-tocopherol from 17.6 to $37.8 \mu \mathrm{g} /$ $\mathrm{g}$ of milk fat over 2 wk. Focant et al. (1998) supplemented cow diets with $\alpha$-tocopherol and oilseeds and, although $\alpha$-tocopherol levels in milk increased from 44.37 to $84.59 \mathrm{mg} / \mathrm{kg}$ of fat, an increase in milkfat oxidation was observed, as measured with the Rancimat apparatus. They attributed this to the increase in unsaturated fatty acids (especially linolenic acid) in milk as a result of a high oilseed diet. Postharvest fortification of milk with a single addition of antioxidants has been studied. Rosenthal et al. (1993) added ascorbic acid (1 $\mathrm{g} / \mathrm{mL}$ ) to whole milk (approximately $3.5 \%$ milk fat) to evaluate milk fat stability. They found that these levels of ascorbic acid negatively influenced milk flavor based on sensory results. In addition, no differences in oxidation levels were observed in fortified milk (TBARS value $=0.61 \mathrm{mg} / \mathrm{kg})$ and control milk $($ TBARS value $=$ $0.71 \mathrm{mg} / \mathrm{kg}$ ) over $7 \mathrm{wk}$ of storage in the dark. In our study, the highest addition of ascorbic acid to milk was at $0.05 \%(0.05 \mathrm{~g} / \mathrm{mL})$. Even at these low levels, sensory differences were detected in unspiked and treated milk. For this reason, this treatment was not used when evaluating the decrease in oxidation flavor in light-exposed milk, because the presence of ascorbic acid at $0.05 \%$ will yield sensory differences.

\section{Chemical Analysis}

The TBARS test largely measures malondialdehyde, a secondary oxidation product, and reports results as milligrams of malondialdehyde per kilogram of sample. The TBARS results supported sensory data. Milk that was exposed to light for $10 \mathrm{~h}$ had a significantly higher TBARS value than milk that was protected from light or milk that was treated with TOC/ASC (Table 4). It is interesting to see that milks treated with antioxidants showed significantly lower levels of oxidation than milk protected from light. Rosenthal et al. (1993) reported comparable levels of TBARS $(0.61 \mathrm{mg} / \mathrm{kg})$ for whole milk that was stored in the dark for $7 \mathrm{~d}$. Angulo et al. (1997) evaluated lipid oxidation in whole milk powder and skim milk powder after $1 \mathrm{yr}$ of storage in the dark at 32 and $55^{\circ} \mathrm{C}$, and under oxygen or nitrogen. The TBARS values for skim milk powder at $32^{\circ} \mathrm{C}$ under air and whole milk powder at $55^{\circ} \mathrm{C}$ under air were 0.29 and $3.69 \mathrm{mg} / \mathrm{kg}$, respectively. Because whole milk powder 
Table 4. Thiobarbituric acid reactive substances test (TBARS) values for light-exposed and light-protected control and antioxidant-treated milk.

\begin{tabular}{ll}
\hline Treatment $^{1}$ & $\begin{array}{l}\text { TBARS value } \\
(\mathrm{mg} / \mathrm{kg})\end{array}$ \\
\hline Milk (light-protected) & $0.59 \pm 0.18^{\mathrm{a}}$ \\
Milk (light-exposed) & $0.92 \pm 0.09^{\mathrm{b}}$ \\
Milk $+0.025 \%$ ASC, $^{2}+0.025 \%$ Toc $^{2}$ (light-exposed) & $0.26 \pm 0.09^{\mathrm{c}}$ \\
\hline
\end{tabular}

${ }^{\mathrm{a}-\mathrm{c}}$ Means $(\mathrm{n}=3)$ with different superscripts are significantly different $(P<0.05)$

${ }^{1}$ Light treatment $=1100$ to $1300 \mathrm{~lx}$ for $10 \mathrm{~h}$.

${ }^{2} \mathrm{ASC}=$ Ascorbic acid; TOC $=\alpha$-tocopherol.

consists of approximately $26 \%$ fat, a high TBARS value is expected compared with skim milk powder with a fat content of $<0.5 \%$ and reduced fat milk. Fenaille et al. (2001) evaluated malondialdehyde concentration as a measure of oxidation in 4 commercial milk powders. The TBARS values ranged from 1.02 to $1.31 \mathrm{mg} / \mathrm{kg}$.

Gas chromatography-olfactometry was used for identifying and rating intensities of odor-active compounds that contribute to milk flavor and light-activated flavor. Compounds such as hexanal, heptanal, and 1-octene3-one are common light-activated flavors that impart grassy, cabbage, and mushroom odors, respectively (Cadwallader and Howard, 1998). In this study, it is interesting to note that light-exposed antioxidanttreated milk samples (TOC/ASC and TOC) showed more odor-active compounds than light-exposed control milk. Odor compounds such as 2-heptanone (nutty), 1octanal (cooked, green, grassy), and nonanal (sweet, plastic) were observed in antioxidant-treated samples (Table 5). It also is interesting to note that, with light exposure, the addition of TOC seemed to increase the intensities of the aroma-active compounds, which could be an indication of a pro-oxidant effect of the antioxi- dant (Frankel, 1998). Figure 1 shows that relative peak areas for hexanal were substantially higher when milk was treated with TOC as compared with control milk and milk treated with TOC/ASC.

Many studies have determined odorous oxidation compounds in control and light-treated dairy products by GC-O. However, few GC-O data are available to show the effect of antioxidants on control and light-treated milk. Cadwallader and Howard (1998) evaluated control and light-activated flavored milk by GC-O and sensory analysis and found that green cut grass (hexanal), mushroom (1-octen-3-one and 1-nonen-3-one), and plastic (1-hexen-3-one) were odors predominant in lightactivated flavor after $48 \mathrm{~h}$ of light exposure at 2200 lux. Although the aroma of light-activated flavor in milk is impacted by fat level, protein oxidation also plays a role to produce odorous compounds such as dimethyl disulfide. Friedrich and Acree (1998) studied the effects on heating, which accelerated lipid auto-oxidation, on milk. Milk that was heat-treated (HTST pasteurized and UHT processed) showed high levels of hexanal, 2nonanone (grassy-herbal, green-fruity), benzothiozole (quinoline, rubbery), and $\delta$-decalactone (coconut). Jung et al. (1998) reported that the reaction of singlet oxygen with sulfur-containing proteins and amino acids is able to produce sulfur-containing volatile compounds such as dimethyl disulfide and identified that compound as the agent responsible for the off-flavor of light-exposed milk. Kim and Morr (1996) and Marsili (1999) stated that the "sunlight" or "burnt feather" flavor occurring after an exposure of milk to visible or ultraviolet light was related to the oxidative degradation of its sulfurcontaining protein fraction, and the "cardboard" flavor, which appeared after a more prolonged exposure to the light, was related to the oxidation of the lipid fraction. In our study, hexanal, a typical lipid oxidation product did not show up in control milk or milk treated with

Table 5. Odor-active compounds ${ }^{1}$ detected by gas chromatography-mass spectrometry of control and antioxidant-treated milk exposed to light (1100-1300 lx) for $10 \mathrm{~h}$.

\begin{tabular}{llllll}
\hline & \multicolumn{2}{c}{$\begin{array}{l}\text { Retention } \\
\text { time }\end{array}$} & & \multicolumn{3}{c}{ Treatment $^{3}$} \\
\cline { 4 - 5 } Compound $^{2}$ & $(\mathrm{~min})$ & Odor description & Control & $0.025 \%$ ASC + & $0.05 \%$ \\
\hline Dimethyl disulfide & 4.42 & Cooked milk & ++ & nd & TOC \\
Hexanal & 4.72 & Grass & nd & nd & ++ \\
2-Heptanone & 6.10 & Nutty & nd & + & +++ \\
n-Heptanal & 6.82 & Rancid/cabbage & + & + & ++ \\
1-Octene-3-ol & 7.30 & Nut/mushroom & + & ++ & ++ \\
1-Octanol & 8.47 & Cooked/green/grassy & nd & + & nd \\
Nonanal & 8.65 & Plastic/sweet & nd & + & +++ \\
\hline
\end{tabular}

${ }^{1}$ Odor intensities: $+(0$ to 1$),++(2$ to 3$),+++(4$ to 5$)$, nd (not detected).

${ }^{2}$ Compound identified by comparison of its mass spectrum.

${ }^{3}$ Retention times from gas chromatography-olfactometry data.

${ }^{4} \mathrm{TOC}=\alpha$-Tocopherol; ASC $=$ ascorbic acid. 


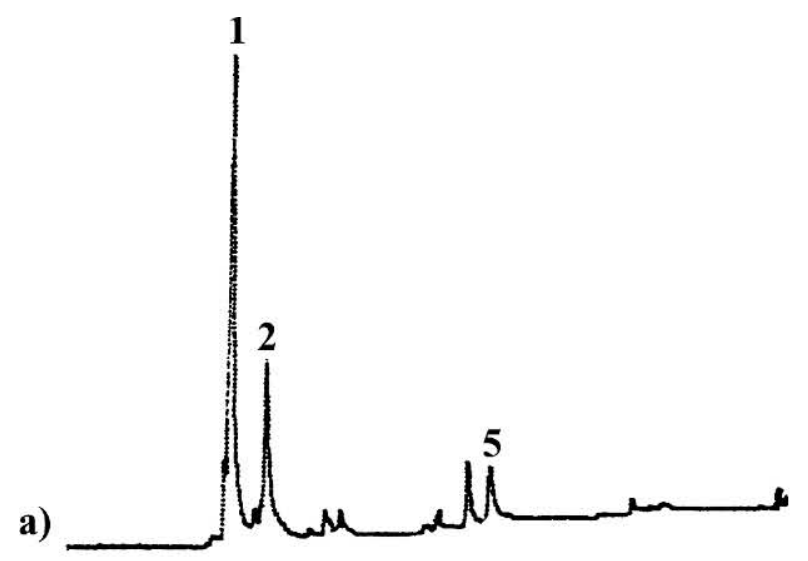

b)

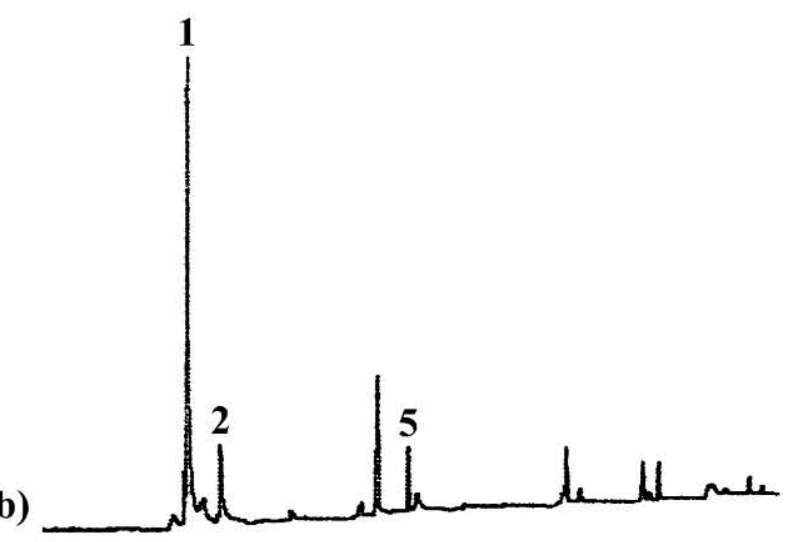

c)

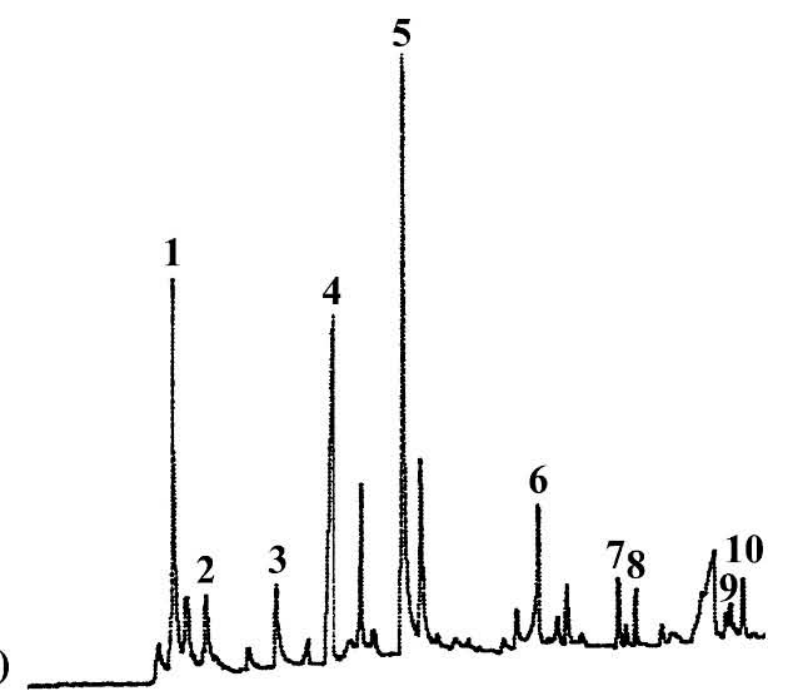

Figure 1. Volatile compounds detected by gas chromatographymass spectrometry of (a) control milk, (b) milk with $0.025 \%$ ascorbic acid and $0.025 \% \alpha$-tocopherol, and (c) milk with $0.05 \% \alpha$-tocopherol added. Light exposure (1300 lx) was applied for $10 \mathrm{~h}$. Peak $1=2$ propanone; $2=2$-butanone; $3=$ pentanal; $4=$ dimethyl disulfide; $5=$ n-hexanal; $6=2$-heptanone; $7=$ n-heptanal; $8=1$-oceten-3-ol; $9=$ octanal; 10 = nonanal. low antioxidant levels. As expected, this indicated that light-induced flavors were not present in light-protected milk and light-exposed milk treated with low levels of antioxidants.

One would expect protein oxidation to have a larger effect on milk samples exposed to only $10 \mathrm{~h}$ of light at 1300 lux. However, dimethyl disulfide, a protein oxidation product, was observed in control milk and milk treated with TOC, whereas it was significantly decreased in milk with added TOC/ASC. This could be explained by the mechanism of the antioxidants. Protein oxidation is not a free-radical chain mechanism as is seen in lipid oxidation, therefore one would not expect a primary antioxidant such as $\alpha$-tocopherol to have an effect on it. However, singlet oxygen is involved in protein oxidation and ascorbic acid is a singlet oxygen quencher, therefore one would expect there to be less dimethyl disulfide in milk with added ascorbic acid.

Although GC-O data suggested the presence of substantially more odorous flavor compounds in antioxidant-treated light-exposed milk, these compounds could be below human detection thresholds in the sample matrix, which might indicate why sensory results did not indicate an increased light oxidation flavor.

\section{CONCLUSION}

Sensory analysis showed that TOC/ASC was the only treatment that did not negatively affect fresh milk flavor and limited light-induced flavor in milk after $10 \mathrm{~h}$ of light exposure. On the other hand, addition of TOC to milk did not negatively influence fresh milk flavor, but it did not limit oxidation flavor in milk that was exposed to $10 \mathrm{~h}$ of light. Because light-activated flavor in milk is comprised of lipid and protein oxidation products, it is important to know the point during light exposure that odorous flavor compounds increase to levels above the human detection threshold. In this study, volatile compounds mostly associated with protein oxidation were measured because milk was exposed for a short period $(10 \mathrm{~h})$. This study shows that the addition of a combination of $0.025 \% \alpha$-tocopherol (1.25\% $\alpha$-tocopherol per gram of fat) and $0.025 \%$ ascorbic acid to reduced fat milk protected milk flavor.

\section{ACKNOWLEDGMENTS}

Funding for this project was provided by Dairy Management Inc., Rosemont, IL. This material is based on work supported by the Cooperative State Research, Education and Extension Service, USDA, under Project No. VA-135704. Any opinions, findings, conclusions, or recommendations expressed in this publication are those of the authors and do not necessarily reflect the view of USDA. 


\section{REFERENCES}

Angulo, A. J., J. M. Romera, M. Ramirez, and A. Gil. 1997. Determination of cholesterol oxides in dairy products: Effect of storage conditions. J. Agric. Food Chem. 45:4318-4323.

Bandarra, N. M., R. M. Campos, I. Batista, M. L. Nunes, and J. M. Empos. 1999. Antioxidant synergy of alpha-tocopherol phospholipids. J. AOCS 76:905-913

Cadwallader, K. R., and C. L. Howard. 1998. Analysis of AromaActive Components of Light Activated Milk. Pages 343-358 in Flavor Analysis: Developments in isolation and characterization/ ACS Symposium Series. No. 700. American Chemical Society, Washington, DC.

Charmley, E., and J. W. G. Nicholson. 1993. Injectable $\alpha$-tocopherol for control of oxidized flavor in milk from dairy cows. Can. J. Anim. Sci. 73:381-392.

Christie, W. W. 1983. Composition and structure of milk lipids. Ch. 1. Pages 1-35 in Developments in Dairy Chemistry-2. P. F. Fox, ed. Applied Science Publishers, New York, NY.

Deeth, H. C. 1997. The role of phospholipids in the stability of milkfat globules. Austral. J. Dairy Technol. 52:44-46.

Fenaille, F., P. Mottier, R. J. Turesky, S. Ali, and P. A. Guy. 2001. Comparison of analytical techniques to quantify malondialdehyde in milk powders. J. Chromatogr. A 921:237-245.

Focant, M., E. Mignolet, M. Marique, F. Clabots, T. Breyne, D. Dalemans, and Y. Larondelle. 1998. The effect of vitamin E supplementation of cow diets containing rapeseed and linseed on the prevention of milkfat oxidation. J. Dairy Sci. 81:1095-1101.

Frankel, E. N. 1998. Antioxidants. Pages 129-166 in Lipid Oxidation. The Oily Press Ltd, Dundee, Scotland.

Friedrich, J. E., and T. E. Acree. 1998. Gas chromatography olfactometry (GC/O) of dairy products. Int. Dairy J. 8:235-241.

Huang, S. W., A. Hopia, K. Schwarz, E. N. Frankel, and J. B. German. 1996. Antioxidant activity of $\alpha$-tocopherol and Trolox in different lipid substrates: Bulk oils vs. oil-in-water emulsions. J. Agric. Food Chem. 44:444-452.

Jadhav, S. J., S. S. Nimbalkar, A. D. Kulkarni, and D. L. Madhavi. 1996. Lipid oxidation in biological and food systems. Pages 5-64 in Food Antioxidants: Technological, Toxicological, and Health
Perspectives. D. L. Madhavi, S. S. Deshpande, and D. K. Salunkhe, ed. Marcel Dekker, Inc., New York, NY.

Jensen, S. K., and K. N. Nielsen. 1996. Tocopherols, retinol, $\beta$-carotene and fatty acids in fat globule core in cows' milk. J. Dairy Res. 63:565-574.

Jung, M. Y., S. H. Yoon, H. O. Lee, and D. B. Min. 1998. Singlet oxygen and ascorbic acid effects on dimethyl disulfide and offflavor in skim milk exposed to light. J. Food Sci. 63:408-412.

Kim, Y. D., and C. V. Morr. 1996. Dynamic headspace analysis of light activated flavor in milk. Int. Dairy J. 6:185-193.

Lawless, H. T., and H. Heymann. 1998. Sensory Evaluation of Food: Principles and Practices. Chapman \& Hall, New York, NY.

Madhavi, D. L., S. S. Deshpande, and D. K. Salunkhe. 1996. Introduction. Pages 1-4 in Food Antioxidants: Technological, Toxicological, and Health Perspectives. D. L. Madhavi, S. S. Deshpande, and D. K. Salunkhe, ed. Marcel Dekker, Inc. New York, NY.

Marsili, R. T. 1999. Comparison of solid-phase microextraction and dynamic headspace methods for the gas chromatographic mass spectrometric analysis of light-induced lipid oxidation products in milk. J. Chromatogr. Sci. 37:17-23.

Mei, L., D. J. McClements, and E. A. Decker. 1999. Lipid oxidation in emulsions as affected by charge status of antioxidants and emulsion droplets. J. Agric. Food Chem. 47:2267-2273.

Meilgaard, M., G. V. Civille, and B. T. Carr. 1999. Sensory Evaluation Techniques. 3rd ed. CRC Press, Inc., Washington, DC.

Rosenthal, I., B. Rosen, and S. Bernstein. 1993. Effects of milk fortification with ascorbic acid and iron. Milchwissenschaft 48:676-679.

SAS Institute. 1998. SAS User's Guide. Statistics, Version 7 ed. SAS Inst., Inc., Cary, NC.

Spanier, A. M., and R. D. Traylor. 1991. A rapid, direct chemical assay for the quantitative determination of thiobarbituric acid reactive substances in raw, cooked, and cooked/stored muscle foods. J. Muscle Foods 2:165-176.

Wessling, C., T. Nielsen, A. Leufven, and M. Jagerstad. 1999. Retention of $\alpha$-tocopherol in low-density polyethylene (LDPE) and polypropylene (PP) in contact with foodstuffs and food-simulating liquids. J. Sci. Food Agric. 79:1635-1641.

Yang, T. S. 1994. Effects of synthetic food colorants on singlet oxygen oxidation of foods. Ph.D. Dissertation, Ohio State Univ., Columbus, $\mathrm{OH}$. 